\title{
PERSPECTIVAS DE EXPANSÃO DA PREVIDÊNCIA PRIVADA FECHADA NO BRASIL
}

Flávio Marcílio Rabelo

Professor do Departamento de Administração Geral e Recursos Humanos da EAESP/FGV.

E-mail: frabelo@fgvsp.br

\section{RESUMO}

O artigo discute os principais condicionantes da expansão da previdência privada fechada no Brasil. A análise destaca a importância de fatores como a distribuição da renda, a distribuição do emprego formal de acordo com o tamanho do estabelecimento e 0 setor de atividade econômica e 0 grau de formalização do mercado de trabalho. Procura-se mostrar que o diferencial de custo não é o principal obstáculo à difusão de planos privados entre as pequenas empresas. Explora-se a viabilidade de algumas medidas voltadas a favorecer a expansão do grau de cobertura da previdência privada fechada no país. A regulamentação de planos criados por entidades de classe e a definição de um tratamento tributário adequado são algumas das alternativas tratadas.

\begin{abstract}
This article discusses the main determinants of the expansion of corporate pension plans in Brazil. Among the factors emphasized in this analysis are income distribution, employment distribution according to firm size and sector of economic activity and the degree of labor market formalization. It is shown that cost differential is not the main barrier to the diffusion of private pension plans among small firms. The article also explores the feasibility of certain measures destined to further the expansion of corporate pension plan coverage in the country. Among these measures, allowance for the creation of pension plans by professional associations and the establishment of an adequate fiscal treatment are highlighted.
\end{abstract}

PALAVRAS-CHAVE

Previdência privada, distribuição de renda, emprego, mercado de trabalho, seguridade.

KEY WORDS

Private pensions, income distribution, employment, labor market, social security. 


\section{INTRODUÇÃO}

O crescente envelhecimento da população, aliado a problemas fiscais enfrentados por vários países, tem despertado mundialmente uma preocupação com a reforma dos sistemas de previdência social (Banco Mundial, 1994). Os sistemas tradicionais de benefício definido funcionando em regime de repartição apresentam graves problemas de financiamento em vários países. As mudanças nos parâmetros do sistema (idades mínimas de acesso aos benefícios e fórmulas de cálculo do benefício) são medidas importantes de saneamento, mas dificilmente representarão, por si só, uma resposta adequada à magnitude do problema enfrentado.

Uma reforma mais ampla no sistema público de previdência social requer a expansão de um sistema complementar privado operando em regime de capitalização. O crescimento do sistema privado permite reduzir o escopo do sistema público, cuja atenção se volta, assim, basicamente às camadas de baixa renda da população. Desse modo, o sistema público consegue cumprir com mais eficiência sua missão de universalizar os benefícios da previdência social. Os indivíduos com rendimentos maiores buscariam no sistema privado o atendimento da maior parte de suas necessidades de renda na aposentadoria ou em estados de invalidez. Os países que conseguiram equacionar melhor o problema de financiamento da previdência social - os Estados Unidos e o Reino Unido - implementaram justamente um modelo com tais características.

O desafio do qual se pretende tratar neste artigo é justamente o da expansão da previdência privada. Oficialmente, os regimes privados de previdência complementar existem há mais de 20 anos no Brasil, mas a taxa de cobertura alcançada ainda é irrisória. Mesmo nos Estados Unidos e no Reino Unido, a previdência privada cobre pouco mais de $50 \%$ da população empregada no setor privado e esse percentual tem se mantido estagnado há muitos anos. Essa cobertura também tende a concentrar-se nos segmentos de alta renda. Um trabalho recente (Orszag, 2000) revela que, enquanto somente $27 \%$ dos trabalhadores empregados em tur- no completo no setor privado dos EUA com rendimentos anuais entre US\$ 10 mil e US\$ 15 mil possuíam um plano privado de previdência, esse percentual subia para $81 \%$ quando se tratava daqueles com rendimentos anuais superiores a US\$ 75 mil.

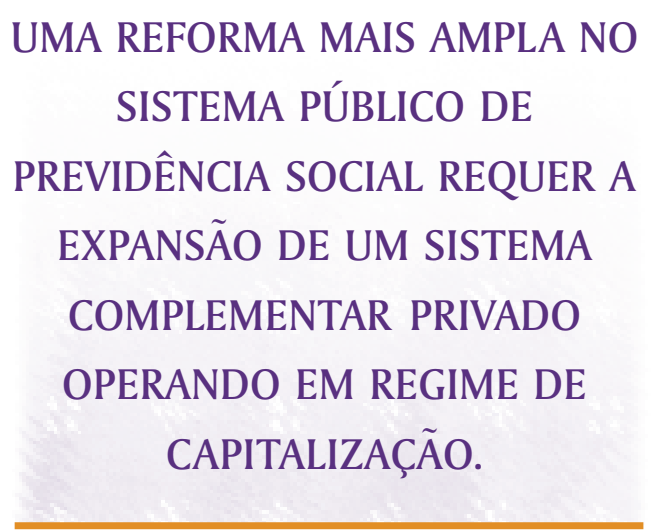

Algumas explicações para a baixa cobertura da previdência privada focam os aspectos regulatórios e tributários desses planos, enquanto outras enfatizam características demográficas da população. A primeira seção deste artigo contrasta essas duas perspectivas e discute os condicionantes estruturais do crescimento da previdência privada fechada. ${ }^{1}$ Com esse intuito, essa seção aborda estudos recentes sobre a cobertura do sistema fechado nos Estados Unidos, onde, apesar do grau razoável de cobertura já atingido, este permanece praticamente inalterado há mais de 20 anos. Essa análise permite destacar limitações estruturais importantes, que, certamente, se fazem presentes em maior intensidade no Brasil: a distribuição da renda e a composição do emprego.

A seguir, analisa-se a situação atual da previdência privada fechada no Brasil com base nos dados disponíveis na Pesquisa Nacional por Amostra de Domicílio (PNAD) e na Relação Anual de Informações Sociais (RAIS), referentes a 1997. Observamse, então, o grau de cobertura atual da previdência privada no Brasil e os condicionantes considerados fundamentais para a expansão. Por fim, analisamse algumas medidas que poderiam contribuir para a ampliação do grau de cobertura da previdência privada fechada no Brasil.

\section{CONDICIONANTES DA EXPANSÃO DA PREVIDÊNCIA PRIVADA FECHADA:} A EXPERIÊNCIA DOS ESTADOS UNIDOS

A experiência americana recente ilustra bem a natureza de algumas dificuldades estruturais para 
aumentar o grau de cobertura da previdência privada fechada. A partir do momento em que foram introduzidos incentivos fiscais à previdência privada nas primeiras décadas deste século, a cobertura do sistema experimentou forte crescimento; o percentual da força de trabalho coberto por planos fechados passou de 15\% no início da Segunda Guerra para $45 \%$ de todos os empregados assalariados do setor privado em 1975. O problema é que, desde

\section{UM ASPECTO RELEVANTE PARA A ANÁLISE DO POTENCIAL DE EXPANSÃO DA PREVIDÊNCIA PRIVADA É A DISTRIBUIÇÃO DA RENDA.}

então, apesar de uma série de iniciativas governamentais, essa taxa de cobertura não aumentou (Hinz e Turner, 1998). Os dados mostram que, dos cerca de 96 milhões de trabalhadores assalariados do setor privado, quase 51 milhões não usufruem do benefício de um plano privado de previdência oferecido pelo empregador.

Hinz e Turner (1998) argumentam que a maioria dos estudos enfoca esse fenômeno da estagnação da taxa de cobertura como um problema de oferta, de modo que a solução seria conceber políticas que facilitassem a adoção de planos privados pelas empresas. Os autores apontam, contudo, que a questão dos custos associados ao provimento de planos fe- chados não é a única explicação. Reconhecem que essa é uma variável importante, mas expõem também que, embora tenha havido uma grande quantidade de medidas que alteraram o custeio de tais planos (requisitos mais rígidos de funding, redução de benefícios tributários), a taxa de cobertura permaneceu inalterada entre 1972 e 1993.

De fato, à primeira vista, os dados parecem confirmar a perspectiva do lado da oferta. As informações do Current Population Survey de 1993 indicam que pouco mais de $59 \%$ da força de trabalho empregada no setor privado trabalhava em empresas que oferecem planos de previdência privada. Destes, $90 \%$ participavam do plano oferecido pelo empregador, resultando na taxa de cobertura total de $45 \%$. Quando se observam as características associadas às firmas que oferecem planos privados, chega-se à segunda conclusão mais comum na discussão do grau de cobertura: que o problema da oferta está ligado às pequenas empresas e que se trata de um diferencial de custo. Observa-se, facilmente, a relação entre grau de cobertura e tamanho da empresa (Tabela 1). Por outro lado, os estudos existentes sobre custeio administrativo de fundos de pensão comprovam que há importantes ganhos de escala na administração desses planos; o custo administrativo per capita para as menores empresas chega a ser quase oito vezes maior do que o das maiores, no caso de planos de contribuição definida. Aceita essa análise, a de-

Tabela 1 - Grau de cobertura e tamanho do estabelecimento ${ }^{2}$

\begin{tabular}{|l|l|l|}
\hline \multicolumn{2}{|l|}{ Taxa estimada de cobertura (\%) } \\
\hline Número de empregados & $\begin{array}{l}\text { Current Population Survey (CPS) de } \\
\text { maio de 1993 - Pension Supplement } \\
\text { (universo de 12.775 observações) }\end{array}$ & $\begin{array}{l}\text { Current Population Survey (CPS) de } \\
\text { março de 1992-1993 (universo de 79.708 } \\
\text { observações) }\end{array}$ \\
\hline De 1 a 9 & 12,0 & 11,9 \\
\hline De 10 a 24 & 24,0 & 21,6 \\
\hline De 25 a 49 & 30,5 & \\
\hline De 50 a 99 & 45,7 & 33,1 \\
\hline De 100 a 249 & 54,5 & 47,6 \\
\hline De 250 a 499 & 63,4 & 57,5 \\
\hline De 500 a 999 & 61,3 & 65,7 \\
\hline 1.000 e acima & 71,5 & 44,8 \\
\hline Todos os tamanhos & 51,1 & \\
\hline
\end{tabular}

Fonte: Even e MacPherson (1996). 
corrência lógica seria pensar medidas que reduzissem o custo de provimento de planos das pequenas empresas (simplificação da regulação, maiores incentivos tributários, etc.).

Uma outra perspectiva para o problema emerge quando se analisam as características dos trabalhadores de empresas que não oferecem planos de previdência: eles tendem a ganhar menos que os trabalhadores de empresas que oferecem planos e a apresentar rotatividade bem superior à destes últimos. O problema, então, pode não ser exatamente o custo de prover o plano, mas sim vir do lado da demanda: o fato de que os trabalhadores de pequenas empresas, dados seus rendimentos, escolaridade e expectativa de permanência no emprego, preferem um aumento no seu salário direto ao benefício de um plano de previdência privada. Hinz e Turner (1998) indicam que os trabalhadores de empresas que não oferecem planos partilham muitas características daqueles que trabalham em empresas que os oferecem, mas dos quais se recusam a participar.

Essa linha de argumentação encontra apoio em The 1999 Small Employer Retirement Survey (SERS) realizado pelo Employee Benefit Research Institute (EBRI) dos Estados Unidos. Os resultados desse levantamento mostram que os custos e a carga administrativa impostos pelo aparato regulatório não constituem o principal óbice à difusão de planos fechados entre as empresas com 100 ou menos funcionários, apesar de esse problema também ter sido apontado pelos entrevistados.

As principais razões para o não-oferecimento de planos fechados de previdência são relacionadas às características da força de trabalho e à incerteza em relação ao faturamento. Os resultados do levantamento revelam claras diferenças nas características dos empregados de pequenas empresas que oferecem planos e nas daqueles que trabalham em empresas sem planos. Trabalhadores com características demográficas tipicamente associadas à falta de preparação para a aposentadoria - mais jovens e de baixa renda, por exemplo - representam um contingente bem maior de emprego nas empresas que não oferecem planos de previdência do que na- quelas que o fazem. O principal obstáculo parece ser a própria realidade de gerir uma pequena empresa: a receita gerada é muito incerta para que a empresa possa comprometer-se com um plano. Além disso, em muitos casos, um plano de previdência não é uma prioridade dos empregados ou, então, a rotatividade é tão elevada que não se justifica patrocinar um plano de previdência.

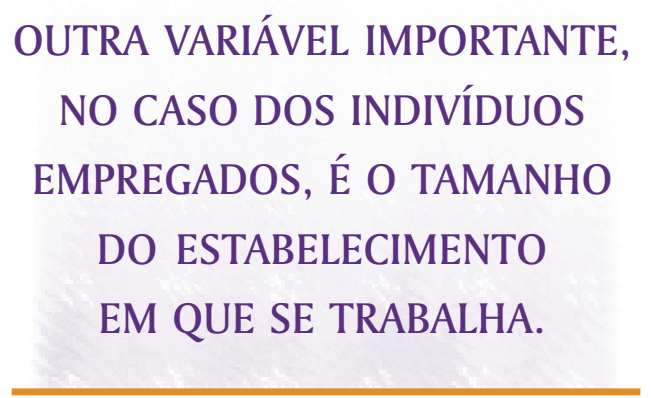

As empresas que não oferecem planos mencionam, entre os fatores que mais provavelmente as levariam a considerar seriamente a possibilidade de oferecer um plano, um aumento dos lucros e de créditos tributários. Entre as pequenas empresas que oferecem planos, as principais razões citadas para assim proceder foram: a) o efeito positivo sobre a atitude e o desempenho dos funcionários e b) as vantagens competitivas obtidas em termos de atração e retenção de funcionários.

Em termos práticos, o enfoque do lado da oferta procura criar condições para reduzir os custos de provimento de planos pelas pequenas empresas - o exemplo mais recente disso é o Savings Incentive Match Plan for Employees (SIMPLE), voltado aos empregadores com 100 ou menos funcionários que ganham US\$ 5 mil ou mais ao ano. Esse novo plano foi instituído em agosto de 1996 e trata-se, essencialmente, de uma tentativa de reduzir a carga administrativa e financeira ligada à criação e manutenção de um plano de previdência privada. Os efeitos máximos de políticas dessa natureza podem ser simulados simplesmente tratando os trabalhadores de pequenas empresas como se estivessem empregados em grandes.

Uma política orientada pelo lado da demanda procuraria, por exemplo, criar mecanismos para atingir os trabalhadores de pequenas empresas com características (rendimentos, idade, status do trabalho, tempo no emprego, etc.) que indicassem alta probabilidade de demandar um plano de previdência privado. Tome-se o exemplo de um engenheiro relativamente bem remunerado, empregado numa peque- 
na empresa na qual a maior parte dos trabalhadores ganha muito pouco e experimenta alta rotatividade. Dificilmente esse indivíduo terá acesso a um plano do empregador, mas é provável que ele deseje participar de um plano fechado instituído por sua associação profissional.

Infelizmente, não se dispõe, no caso brasileiro, de muitas informações a respeito das características dos indivíduos cobertos pela previdência privada fechada. A análise será conduzida, portanto, considerando apenas o rendimento e o tamanho do estabelecimento como variáveis explicativas.

\section{CONDICIONANTES DA EXPANSÃO DA PREVIDÊNCIA PRIVADA FECHADA NO BRASIL}

Os dados da Pesquisa Nacional por Amostra de Domicílios (PNAD) de 1997 revelam uma População Economicamente Ativa (PEA) em torno de 75 milhões de pessoas (Tabela 2). Deve-se observar, porém, que, devido à relativamente pouca idade em que os brasileiros se aposentam e à não-exigência de retirada formal do mercado de trabalho, há, na PEA, um número não desprezível de aposentados e pensionistas. Quando se exclui esse grupo, o universo reduz-se a aproximadamente 70 milhões de pessoas.

Um aspecto relevante para a análise do potencial de expansão da previdência privada é a distribuição da renda. A Tabela 2 mostra uma distribuição bastante desfavorável ao crescimento da previdência privada. As pessoas com rendimentos mensais acima de dez salários mínimos representam apenas $6,9 \%$ da PEA (sem os aposentados e pensionistas); já aquelas com até três salários mínimos representam cerca de $50 \%$. O referencial de dez salários mínimos é importante, dado que, nos últimos anos, este tem servido como um teto para cobrança e pagamento de benefícios do Regime Geral de Previdência Social (RGPS). Costuma-se tratar as pessoas com rendimentos acima desse teto como um público-alvo potencial para a previdência privada. A Tabela 2 indica, portanto, um primeiro segmento potencial composto de 4,8 milhões de pessoas.

Um outro elemento que contribui desfavoravelmente para a expansão da previdência privada fechada no Brasil é o elevado grau de informalização do mercado de trabalho (Tabelas 3 e 4). Os indivíduos classificados como "empregados" respondem por apenas $52 \%$ do total de pessoas ocupadas e, dentre os "empregados", $32 \%$ estão classificados como "outros e sem declaração". Além disso, dos indivíduos com mais de dez salários mínimos da PEA (excluindo aposentados e pensionistas), $26,7 \%$ pertencem à categoria de ocupação "conta própria". As pessoas classificadas como "empregados com carteira assinada" (de onde se excluem os militares e funcionários públicos estatutários) representam $28,7 \%$ do total de pessoas ocupadas e $37 \%$ dos indivíduos com mais de dez salários mínimos, enquanto apenas quatro profissões liberais típicas englobam em torno de $9 \%$ desse último grupo (Tabela 5).

Tabela 2 - Composição da PEA (1997)

\begin{tabular}{|c|c|c|c|}
\hline Faixa de rendimento mensal & Total & $\begin{array}{l}\text { Aposentados e } \\
\text { pensionistas }\end{array}$ & $\begin{array}{c}\text { Sem aposentados e } \\
\text { pensionistas }\end{array}$ \\
\hline Total & 75.213 .283 & 5.270 .270 & 69.943 .013 \\
\hline Até $1 / 2$ salário mínimo & 3.930 .784 & 5.087 & 3.925 .697 \\
\hline Mais de $1 / 2$ a 1 salário mínimo & 10.625 .693 & 1.009 .416 & 9.616 .277 \\
\hline Mais de 1 a 2 salários mínimos & 13.399 .825 & 1.142 .116 & 12.257.709 \\
\hline Mais de 2 a 3 salários mínimos & 9.881 .661 & 702.028 & 9.179 .633 \\
\hline Mais de 3 a 5 salários mínimos & 10.049 .969 & 704.228 & 9.345 .741 \\
\hline Mais de 5 a 10 salários mínimos & 7.441 .855 & 778.866 & 6.662 .989 \\
\hline Mais de 10 a 20 salários mínimos & 3.508 .058 & 470.509 & 3.037 .549 \\
\hline Mais de 20 salários mínimos & 2.072 .598 & 313.675 & 1.758 .923 \\
\hline Sem rendimento & 13.399 .320 & 0 & 13.399 .320 \\
\hline Sem declaração & 903.520 & 144.345 & 759.175 \\
\hline Grupo com mais de 10 salários mínimos & 5.580 .656 & 784.184 & 4.796 .472 \\
\hline
\end{tabular}

Fonte: PNAD (1997). 
Tabela 3 - Faixas de rendimento por posição na ocupação (1997)

\begin{tabular}{|l|r|r|r|r|}
\hline \multicolumn{1}{|c|}{ Faixa de rendimento } & Empregados & Conta própria & Empregadores & Total \\
\hline Até 1/2 salário mínimo & 1.281 .059 & 1.688 .618 & 5.870 & $\mathbf{3 . 8 3 8 . 5 7 6}$ \\
\hline Mais de 1/2 a 1 salário mínimo & 5.178 .020 & 2.213 .478 & 48.704 & $\mathbf{1 0 . 4 5 6 . 3 7 0}$ \\
\hline Mais de 1 a 2 salários mínimos & 8.254 .379 & 3.301 .739 & 121.663 & $\mathbf{1 3 . 2 8 6 . 6 7 5}$ \\
\hline Mais de 2 a 3 salários mínimos & 6.641 .618 & 2.360 .456 & 176.785 & $\mathbf{9 . 8 2 3 . 7 2 6}$ \\
\hline Mais de 3 a 5 salários mínimos & 6.614 .893 & 2.654 .690 & 404.532 & $\mathbf{9 . 9 9 7 . 5 1 8}$ \\
\hline Mais de 5 a 10 salários mínimos & 4.813 .681 & 1.827 .116 & 652.650 & $\mathbf{7 . 4 0 1 . 9 1 6}$ \\
\hline Mais de 10 a 20 salários mínimos & 1.963 .029 & 852.239 & 652.647 & $\mathbf{3 . 4 9 4 . 7 5 4}$ \\
\hline Mais de 20 salários mínimos & 995.971 & 431.038 & 632.974 & $\mathbf{2 . 0 6 7 . 3 2 4}$ \\
\hline Sem rendimento & 27.132 & 28.359 & 4.089 & $\mathbf{8 . 0 6 8 . 7 1 0}$ \\
\hline Sem declaração & 378.538 & 382.874 & 94.890 & $\mathbf{8 9 5 . 9 3 8}$ \\
\hline Total & $\mathbf{3 6 . 1 4 8 . 3 2 0}$ & $\mathbf{1 5 . 7 4 0 . 6 0 7}$ & $\mathbf{2 . 7 9 4 . 8 0 4}$ & $\mathbf{6 9 . 3 3 1 . 5 0 7}$ \\
\hline
\end{tabular}

Fonte: PNAD (1997).

Tabela 4 - Faixas de rendimento por categoria dos empregados (1997)

\begin{tabular}{|l|r|r|r|r|r|}
\hline \multicolumn{1}{|c|}{ Faixa de rendimento } & $\begin{array}{c}\text { Empregados } \\
\text { com carteira } \\
\text { assinada }\end{array}$ & Militares & $\begin{array}{c}\text { Funcionários } \\
\text { públicos } \\
\text { estatutários }\end{array}$ & $\begin{array}{c}\text { Outros e sem } \\
\text { declaração }\end{array}$ & Total \\
\hline Até 1/2 salário mínimo & 64.379 & 1.253 & 30.808 & 1.184 .619 & $\mathbf{1 . 2 8 1 . 0 5 9}$ \\
\hline Mais de 1/2 a 1 salário mínimo & 1.418 .083 & 26.351 & 263.131 & 3.470 .455 & $\mathbf{5 . 1 7 8 . 0 2 0}$ \\
\hline Mais de 1 a 2 salários mínimos & 4.371 .882 & 23.860 & 555.698 & 3.302 .939 & $\mathbf{8 . 2 5 4 . 3 7 9}$ \\
\hline Mais de 2 a 3 salários mínimos & 4.512 .270 & 13.189 & 570.050 & 1.546 .109 & $\mathbf{6 . 6 4 1 . 6 1 8}$ \\
\hline Mais de 3 a 5 salários mínimos & 4.519 .097 & 84.069 & 884.708 & 1.127 .019 & $\mathbf{6 . 6 1 4 . 8 9 3}$ \\
\hline Mais de 5 a 10 salários mínimos & 2.981 .529 & 86.168 & 1.102 .729 & 643.255 & $\mathbf{4 . 8 1 3 . 6 8 1}$ \\
\hline Mais de 10 a 20 salários mínimos & 1.200 .826 & 38.906 & 471.439 & 251.858 & $\mathbf{1 . 9 6 3 . 0 2 9}$ \\
\hline Mais de 20 salários mínimos & 582.967 & 18.531 & 270.785 & 123.688 & $\mathbf{9 9 5 . 9 7 1}$ \\
\hline Sem rendimento & 5.476 & 0 & 0 & 21.656 & $\mathbf{2 7 . 1 3 2}$ \\
\hline Sem declaração & 221.743 & 6.905 & 50.613 & 99.277 & $\mathbf{3 7 8 . 5 3 8}$ \\
\hline Total & $\mathbf{1 9 . 8 7 8 . 2 5 2}$ & $\mathbf{2 9 9 . 2 3 2}$ & $\mathbf{4 . 1 9 9 . 9 6 1}$ & $\mathbf{1 1 . 7 7 0 . 8 7 5}$ & $\mathbf{3 6 . 1 4 8 . 3 2 0}$ \\
\hline
\end{tabular}

Fonte: PNAD (1997).

Tabela 5 - Faixas de rendimento de categorias profissionais selecionadas (1997)

\begin{tabular}{|l|r|r|r|r|r|}
\hline \multicolumn{1}{|c|}{ Faixa de rendimento } & Médico & Dentista & \multicolumn{1}{c|}{ Advogado } & \multicolumn{1}{c|}{ Arquiteto } \\
\hline Até 1/2 salário mínimo & 0 & 0 & 0 & 207 & $\mathbf{2 0 7}$ \\
\hline Mais de 1/2 a 1 salário mínimo & 456 & 1.081 & 506 & 349 & $\mathbf{2 . 3 9 2}$ \\
\hline Mais de 1 a 2 salários mínimos & 3.042 & 1.080 & 1.889 & 0 & $\mathbf{6 . 0 1 1}$ \\
\hline Mais de 2 a 3 salários mínimos & 2.082 & 1.165 & 3.178 & 3.073 & $\mathbf{9 . 4 9 8}$ \\
\hline Mais de 3 a 5 salários mínimos & 5.276 & 3.086 & 14.553 & 817 & $\mathbf{2 3 . 7 3 2}$ \\
\hline Mais de 5 a 10 salários mínimos & 31.349 & 14.529 & 39.781 & 9.821 & $\mathbf{9 5 . 4 8 0}$ \\
\hline Mais de 10 a 20 salários mínimos & 43.130 & 35.231 & 66.207 & 12.986 & $\mathbf{1 5 7 . 5 5 4}$ \\
\hline Mais de 20 salários mínimos & 129.014 & 42.668 & 97.833 & 8.812 & $\mathbf{2 7 8 . 3 2 7}$ \\
\hline Sem rendimento & 0 & 0 & 418 & 0 & $\mathbf{4 1 8}$ \\
\hline Sem declaração & 10.944 & 1.369 & 16.250 & 2.754 \\
\hline Total & $\mathbf{2 2 5 . 2 9 3}$ & $\mathbf{1 0 0 . 2 0 9}$ & $\mathbf{2 4 0 . 6 1 5}$ & $\mathbf{3 8 . 8 1 9}$ & $\mathbf{3 1 . 3 1 7}$ \\
\hline
\end{tabular}

Fonte: PNAD (1997). 
A questão da formalização do mercado é fundamental, pois, nos moldes nos quais a previdência privada fechada está atualmente organizada, ela tem o seu acesso limitado praticamente aos indivíduos com carteira de trabalho assinada. Conforme mostra a Tabela 3, as pessoas ocupadas por conta própria e os empregadores com mais de dez salários mínimos formam um contingente de aproximadamente 2,5 milhões. Uma parte desse grupo pode encontrar cobertura adequada nos planos abertos existentes, mas uma outra parte, particularmente os de rendimentos médios, provavelmente estaria melhor em planos fechados instituídos por órgãos de classe ou sindicatos. ${ }^{3}$ Tais planos podem apresentar, sobretudo, vantagens de custo e flexibilidade para os participantes.

É importante lembrar que o fato de o plano ser oferecido por um sindicato ou uma associação profissional dos quais os indivíduos participam tende a aumentar o grau de confiança no plano. Os instituidores cumpririam um importante papel ao lidarem com o desconhecimento e a desconfiança em relação aos planos de previdência privada. Só entre médicos e advogados, duas categorias com forte filiação aos órgãos profissionais, há 336 mil indivíduos com mais de dez salários mínimos.

A PNAD possui uma variável importante para esse trabalho que é se o indivíduo contribui ou não para a previdência privada, embora a pergunta não distinga entre previdência privada aberta e fechada. Como os dados da PNAD representam uma projeção de uma amostra e o número de pessoas contribuindo para previdência privada é relativamente pequeno, os valores absolutos devem ser vistos com cautela, apesar de serem bastante úteis para análise de alguns fatores que influem no grau de cobertura. A Tabela 6 apresenta o número de contribuin-

Tabela 6 - Contribuição à previdência privada por faixas de rendimento (1997)

\begin{tabular}{|l|c|c|c|}
\hline \multicolumn{1}{|c|}{ Faixa de rendimento } & Contribuintes & $\begin{array}{c}\text { Percentual do total de } \\
\text { contribuintes }\end{array}$ & $\begin{array}{c}\text { Percentual do total de } \\
\text { pessoas na faixa }\end{array}$ \\
\hline Até 1/2 salário mínimo & 8.238 & 0,0037 & 0,0021 \\
\hline Mais de 1/2 a 1 salário mínimo & 75.110 & 0,0338 & 0,0078 \\
\hline Mais de 1 a 2 salários mínimos & 121.059 & 0,0544 & 0,0099 \\
\hline Mais de 2 a 3 salários mínimos & 150.865 & 0,0678 & 0,0164 \\
\hline Mais de 3 a 5 salários mínimos & 279.524 & 0,1257 & 0,0299 \\
\hline Mais de 5 a 10 salários mínimos & 468.868 & 0,2108 & 0,0704 \\
\hline Mais de 10 a 20 salários mínimos & 429.088 & 0,1929 & 0,1413 \\
\hline Mais de 20 salários mínimos & 428.374 & 0,1926 & 0,2435 \\
\hline Sem rendimento & 226.863 & 0,1020 & 0,0169 \\
\hline Sem declaração & 36.163 & 0,0163 & 0,0476 \\
\hline Total & $\mathbf{2 . 2 2 4 . 1 5 2}$ & & $\mathbf{0 , 0 3 1 8}$ \\
\hline
\end{tabular}

Fonte: PNAD (1997).

Tabela 7 - Contribuição à previdência privada segundo posição na ocupação (1997)

\begin{tabular}{|l|c|c|c|}
\hline \multicolumn{1}{|c|}{ Posição na ocupação } & Contribuintes & $\begin{array}{c}\text { Percentual do total } \\
\text { de contribuintes }\end{array}$ & $\begin{array}{c}\text { Percentual de pessoas } \\
\text { na ocupação }\end{array}$ \\
\hline Empregados com carteira assinada & 813.136 & 0,3656 & 0,0409 \\
\hline Funcionários públicos estatutários & 280.454 & 0,1261 & 0,0668 \\
\hline Conta própria & 250.963 & 0,1128 & 0,0159 \\
\hline Empregadores & 238.641 & 0,1073 & 0,0818 \\
\hline Outros & 161.003 & 0,0839 & \\
\hline Total de ocupados & 1.769 .751 & 0,7957 & \\
\hline Não ocupados & 454.401 & 0,2043 & \\
\hline Total & $\mathbf{2 . 2 2 4 . 1 5 2}$ & & \\
\hline
\end{tabular}

Fonte: PNAD (1997). 
tes por faixa de rendimento. A influência da renda na participação e no grau de cobertura, como seria de se esperar, fica evidente: $40 \%$ dos contribuintes encontram-se na faixa superior a 10 salários mínimos e o grau mais elevado de cobertura (24\%) está entre as pessoas com rendimento mensal superior a 20 salários mínimos. Fica claro, também, o baixíssimo grau de cobertura da PEA (excluindo aposentados e pensionistas), que é pouco superior a $3 \%$. Mesmo nas faixas de rendimentos mais elevados, o grau de cobertura é baixo.

Quando se analisa a participação na previdência privada de acordo com a natureza da ocupação (Tabela 7), observa-se que pouco mais de $36 \%$ dos contribuintes são em- pregados com carteira de trabalho assinada, embora o grupo com maior cobertura seja o de empregadores $(8,2 \%)$. Os trabalhadores por conta própria representam cerca de $11 \%$ dos contribuintes e têm uma cobertura bastante baixa $(1,6 \%)$, o que é preocupante, já que esse grupo também apresenta baixo grau de cobertura pela previdência pública. Mesmo os indivíduos que trabalham por conta própria e recebem rendimentos mensais superiores a 20 salários mínimos apresentam um grau de cobertura de apenas 13,3\% (Tabela 8). As Tabelas 9 e 10 mostram o grau de cobertura das ocupações "empregados com carteira assinada" e "empregadores" de acordo com as faixas de rendimento. Nos dois casos, fica evidente a importância do rendimento: o grau de cobertura só atinge valores superiores a 10\% nas faixas com mais de dez salários mínimos.

Tabela 8 - Contribuição à previdência privada por faixa de rendimento das pessoas ocupadas por conta própria (1997)

\begin{tabular}{|l|c|c|}
\hline \multicolumn{1}{|c|}{ Faixa de rendimento } & Conta própria & $\begin{array}{c}\text { Percentual das pessoas } \\
\text { na ocupação }\end{array}$ \\
\hline Até $1 / 2$ salário mínimo & 1.677 & 0,0010 \\
\hline Mais de $1 / 2$ a 1 salário mínimo & 4.157 & 0,0019 \\
\hline Mais de 1 a 2 salários mínimos & 13.891 & 0,0042 \\
\hline Mais de 2 a 3 salários mínimos & 17.612 & 0,0075 \\
\hline Mais de 3 a 5 salários mínimos & 38.864 & 0,0146 \\
\hline Mais de 5 a 10 salários mínimos & 46.677 & 0,0255 \\
\hline Mais de 10 a 20 salários mínimos & 62.180 & 0,0730 \\
\hline Mais de 20 salários mínimos & 57.250 & 0,1328 \\
\hline Sem rendimento & 262 & 0,0092 \\
\hline Sem declaração & 8.393 & 0,0219 \\
\hline Total & $\mathbf{2 5 0 . 9 6 3}$ & $\mathbf{0 , 0 1 5 9}$ \\
\hline
\end{tabular}

Fonte: PNAD (1997).

Tabela 9 - Contribuição à previdência privada por faixa de rendimento das pessoas ocupadas empregadas com carteira assinada (1997)

\begin{tabular}{|l|c|c|}
\hline \multicolumn{1}{|c|}{ Faixa de rendimento } & $\begin{array}{c}\text { Empregados com } \\
\text { carteira assinada }\end{array}$ & $\begin{array}{c}\text { Percentual das pessoas } \\
\text { na ocupação }\end{array}$ \\
\hline Até $1 / 2$ salário mínimo & 0 & 0,0000 \\
\hline Mais de $1 / 2$ a 1 salário mínimo & 13.329 & 0,0094 \\
\hline Mais de 1 a 2 salários mínimos & 54.542 & 0,0125 \\
\hline Mais de 2 a 3 salários mínimos & 77.371 & 0,0171 \\
\hline Mais de 3 a 5 salários mínimos & 136.665 & 0,0302 \\
\hline Mais de 5 a 10 salários mínimos & 197.834 & 0,0664 \\
\hline Mais de 10 a 20 salários mínimos & 178.155 & 0,1484 \\
\hline Mais de 20 salários mínimos & 144.231 & 0,2474 \\
\hline Sem rendimento & 0 & 0,0000 \\
\hline Sem declaração & 11.009 & 0,0496 \\
\hline Total & $\mathbf{8 1 3 . 1 3 6}$ & $\mathbf{0 , 0 4 0 9}$ \\
\hline
\end{tabular}

Fonte: PNAD (1997). 
No item anterior, viu-se que, além da renda, outra variável importante, no caso dos indivíduos empregados, é o tamanho do estabelecimento em que se trabalha. Os dados da PNAD não permitem, infelizmente, cruzar a contribuição à previdência privada com o tamanho do estabelecimento de trabalho. A questão do emprego por tamanho de estabelecimento pode ser tratada, contudo, na Relação Anual de Informações Sociais (RAIS), embora essa base de dados não disponha de informações sobre a participação na previdência privada.

\section{HÁ UMA EVIDENTE CONCENTRAÇÃO DO EMPREGO}

EM PEQUENAS EMPRESAS; 46\% DOS EMPREGOS ESTAVAM ALOCADOS EM EMPRESAS COM MENOS DE 100 EMPREGADOS, ENQUANTO APENAS 26\% SE ENCONTRAVAM EM EMPRESAS COM MAIS DE 1.000 EMPREGADOS.

A Tabela 11 apresenta o universo coberto pela RAIS de 1997, de acordo com a natureza do vínculo empregatício e o setor de atividade econômica. ${ }^{4}$ Em termos da natureza do vínculo empregatício, apenas o grupo de trabalhadores regidos pela CLT interessa à previdência privada fechada, uma vez que os estatutários gozam de um regime próprio de previdência, que assegura uma renda de aposentadoria igual ao último salário, e os demais têm vínculos empregatícios precários. Isso restringe o universo a $18,8 \mathrm{mi}$ lhões de trabalhadores em 1997.

A análise da distribuição do emprego formal de acordo com o tamanho (número de empregados) do empregador pode adotar como unidade de estudo a empresa ou o estabelecimento. Em geral, cada endereço de atuação de uma empresa corresponde a um estabelecimento. Uma vez que a hipótese introduzida no trabalho é a de que o tamanho do empregador influi na probabilidade de ele vir a oferecer um plano privado, a unidade apropriada a essa pesquisa seria a empresa. Os dados disponibilizados pelo Ministério do Trabalho e Emprego estão organizados, contudo, de acordo com a unidade de estabelecimento. Najberg e Oliveira (1999) conseguiram elaborar uma distribuição do emprego formal de acordo com o setor de ocupação e o tamanho da empresa utilizando algumas tabulações especiais da RAIS. As Tabelas 12 e 13 mostram a distribuição do emprego formal (excluindo a administração pública e agropecuária) utilizando estabelecimentos e empresas como unidades de estudo. Apesar das diferenças, há uma evidente concentração do emprego em pequenas empresas; $46 \%$ (56\%) dos empregos estavam alocados em empresas (estabelecimentos) com menos de 100 empregados, enquanto apenas $26 \%(13 \%)$ se encontravam

Tabela 10 - Contribuição à previdência privada por faixa de rendimento das pessoas ocupadas empregadores (1997)

\begin{tabular}{|l|c|c|}
\hline \multicolumn{1}{|c|}{ Faixa de rendimento } & Empregadores & $\begin{array}{c}\text { Percentual das pessoas } \\
\text { na ocupação }\end{array}$ \\
\hline Até $1 / 2$ salário mínimo & 0 & 0,0000 \\
\hline Mais de 1/2 a 1 salário mínimo & 0 & 0,0000 \\
\hline Mais de 1 a 2 salários mínimos & 905 & 0,0074 \\
\hline Mais de 2 a 3 salários mínimos & 5.372 & 0,0304 \\
\hline Mais de 3 a 5 salários mínimos & 11.035 & 0,0273 \\
\hline Mais de 5 a 10 salários mínimos & 35.909 & 0,0550 \\
\hline Mais de 10 a 20 salários mínimos & 60.079 & 0,0921 \\
\hline Mais de 20 salários mínimos & 117.082 & 0,1850 \\
\hline Sem rendimento & 496 & 0,1213 \\
\hline Sem declaração & 7.763 & 0,0818 \\
\hline Total & $\mathbf{2 3 8 . 6 4 1}$ & $\mathbf{0 , 0 8 5 4}$ \\
\hline
\end{tabular}

Fonte: PNAD (1997). 
em empresas (estabelecimentos) com mais de 1.000 empregados. Já foi visto, na seção anterior, que a probabilidade de pequenas empresas oferecerem planos de previdência é baixa. No Brasil, isso deve ser ainda mais acentuado em função de os salários serem mais baixos e de a situação dessas empresas, muito provavelmente, ser mais precária.

Essa baixa probabilidade, como também indicam estudos americanos (Employee
Benefit Research Institute, 1999), está ligada às próprias características demográficas dos funcionários. No caso brasileiro, é interessante comparar a remuneração dos empregados dos diversos tipos de estabelecimento ${ }^{5}$ (Tabela 14): enquanto $60 \%$ dos empregados das empresas de 1 a 99 funcionários ganham até três salários mínimos, esse percentual, nas empresas com mais de 1.000 funcionários, é de $27 \%$. De modo inverso, apenas $7,7 \%$ dos empregados das pequenas empresas ganham mais de dez salários mínimos; já nas em-

Tabela 11 - Trabalhadores em atividade em 31 de dezembro de 1997 segundo vínculo empregatício e setor de atividade econômica (1997)

\begin{tabular}{|l|c|l|r|}
\hline \multicolumn{1}{|c|}{ Vínculo empregatício } & No de indivíduos & \multicolumn{1}{c|}{ Setor de atividade econômica } & № de indivíduos \\
\hline CLT U/PJ IND. & 17.567 .849 & Extração mineral & 105.830 \\
\hline CLT U/PF IND. & 288.168 & Indústria de transformação & 4.703 .756 \\
\hline CLT R/PJ IND. & 252.083 & Serviços industriais de utilidade pública & 1.162 .045 \\
\hline CLT R/PF IND. & 554.012 & Construção civil & 3.668 .782 \\
\hline ESTATUTÁRIO & 4.479 .222 & Comércio & 7.662 .212 \\
\hline ESTAT. N/EFET. & 482.480 & Serviços & 5.441 .855 \\
\hline AVULSO & 121.607 & Administração pública & 997.892 \\
\hline TEMPORÁRIO & 132.772 & Agropecuária & 30.005 \\
\hline CLT U/PJ DET. & 147.598 & Outros/ignorados & \\
\hline CLT U/PF DET. & 4.833 & & \\
\hline CLT R/PJ DET. & 29.937 & & $\mathbf{2 4 . 1 0 4 . 4 2 8}$ \\
\hline CLT R/PF DET. & 17.618 & & \\
\hline DIRETOR & 14.845 & & \\
\hline IGNORADO & $\mathbf{2 4 . 1 0 4 . 4 2 8}$ & & \\
\hline Total & & & \\
\hline
\end{tabular}

Fonte: MTE/RAIS (1997).

Tabela 12 - Distribuição dos trabalhadores em atividade em 31 de dezembro de 1997 segundo o tamanho da empresa e o setor de atividade econômica (em mil trabalhadores)

\begin{tabular}{|c|c|c|c|c|c|c|c|c|c|}
\hline $\begin{array}{l}\text { Número de } \\
\text { empregados }\end{array}$ & $\begin{array}{c}\text { Extração } \\
\text { mineral }\end{array}$ & $\begin{array}{c}\text { Indústria } \\
\text { de } \\
\text { transfor- } \\
\text { mação }\end{array}$ & $\begin{array}{c}\text { Serviços } \\
\text { industriais } \\
\text { de } \\
\text { utilidade } \\
\text { pública }\end{array}$ & $\begin{array}{c}\text { Cons- } \\
\text { trução } \\
\text { civil }\end{array}$ & Comércio & Serviços & Total & $\begin{array}{l}\text { Percen- } \\
\text { tual }\end{array}$ & $\begin{array}{l}\text { Percen- } \\
\text { tual } \\
\text { acumu- } \\
\text { lado }\end{array}$ \\
\hline De 1 a 4 & 5 & 194 & 1 & 72 & 760 & 690 & 1.722 & 9,69 & \\
\hline De 5 a 9 & 6 & 254 & 2 & 75 & 560 & 590 & 1.487 & 8,37 & 18,06 \\
\hline De 10 a 19 & 9 & 357 & 3 & 102 & 508 & 567 & 1.546 & 8,70 & 26,77 \\
\hline De 20 a 49 & 15 & 539 & 7 & 172 & 484 & 749 & 1.966 & 11,07 & 37,83 \\
\hline De 50 a 99 & 13 & 444 & 7 & 142 & 290 & 567 & 1.463 & 8,24 & 46,07 \\
\hline De 100 a 249 & 14 & 635 & 15 & 184 & 293 & 799 & 1.940 & 10,92 & 56,99 \\
\hline De 250 a 499 & 10 & 515 & 14 & 136 & 160 & 673 & 1.508 & 8,49 & 65,48 \\
\hline De 500 a 999 & 11 & 471 & 15 & 102 & 125 & 735 & 1.459 & 8,21 & 73,69 \\
\hline 1.000 ou mais & 11 & 1.195 & 256 & 185 & 507 & 2.519 & 4.673 & 26,31 & 100,00 \\
\hline Total & 94 & 4.604 & 320 & 1.170 & 3.687 & 7.889 & 17.764 & 100,00 & \\
\hline
\end{tabular}

Fonte: Najberg e Oliveira (1999). 
presas com mais de 1.000 empregados, esse percentual sobe quase $30 \%$. É interessante observar, contudo, que há cerca de 770 mil pessoas trabalhando em pequenas empresas com rendimentos mensais superiores a dez salários mínimos. Esses indivíduos são contribuintes potenciais da previdência privada, mas provavelmente não terão acesso a planos fechados oferecidos pelo empregador.

\section{SITUAÇÃO ATUAL E PERSPECTIVAS DA PREVIDÊNCIA PRIVADA FECHADA NO BRASIL}

Com base nos dados apresentados, cabe especular qual seria o potencial de expansão do sistema fechado de previdência privada. O primeiro passo seria olhar o setor

Tabela 13 - Distribuição dos trabalhadores em atividade em 31 de dezembro de 1997 segundo o tamanho do estabelecimento e o setor de atividade econômica

\begin{tabular}{|c|c|c|c|c|c|c|c|c|c|}
\hline $\begin{array}{l}\text { Número de } \\
\text { empregados }\end{array}$ & $\begin{array}{c}\text { Extração } \\
\text { mineral }\end{array}$ & $\begin{array}{l}\text { Indústria } \\
\text { de } \\
\text { transfor- } \\
\text { mação }\end{array}$ & $\begin{array}{c}\text { Serviços } \\
\text { industriais } \\
\text { de } \\
\text { utilidade } \\
\text { pública }\end{array}$ & $\begin{array}{l}\text { Cons- } \\
\text { trução } \\
\text { civil }\end{array}$ & Comércio & Serviços & Total & $\begin{array}{l}\text { Percen- } \\
\text { tual }\end{array}$ & $\begin{array}{l}\text { Percen- } \\
\text { tual } \\
\text { acumu- } \\
\text { lado }\end{array}$ \\
\hline De 1 a 4 & 5.437 & 207.317 & 5.819 & 73.784 & 833.656 & 746.115 & 1.872 .128 & 10,62 & \\
\hline De 5 a 9 & 7.099 & 275.350 & 7.631 & 78.000 & 668.938 & 682.615 & 1.719 .633 & 9,75 & 20,37 \\
\hline De 10 a 19 & 10.745 & 391.979 & 10.232 & 108.945 & 645.220 & 745.815 & 1.912 .936 & 10,85 & 31,22 \\
\hline De 20 a 49 & 19.609 & 604.452 & 20.033 & 185.960 & 607.225 & 1.056 .179 & 2.493 .458 & 14,14 & 45,35 \\
\hline De 50 a 99 & 14.813 & 523.617 & 24.486 & 159.099 & 340.306 & 780.084 & 1.842 .405 & 10,45 & 55,80 \\
\hline De 100 a 249 & 13.283 & 776.402 & 39.534 & 216.155 & 341.993 & 982.786 & 2.370 .153 & 13,44 & 69,24 \\
\hline De 250 a 499 & 13.382 & 652.347 & 34.100 & 148.604 & 138.583 & 767.981 & 1.754 .997 & 9,95 & 79,19 \\
\hline De 500 a 999 & 11.886 & 531.788 & 40.604 & 95.125 & 57.470 & 719.288 & 1.456 .161 & 8,26 & 87,45 \\
\hline 1.000 ou mais & 9.576 & 740.504 & 149.612 & 96.373 & 35.391 & 1.181 .349 & 2.212 .805 & 12,55 & 100,00 \\
\hline Total & 105.830 & 4.703.756 & 332.051 & 1.162 .045 & 3.668 .782 & 7.662.212 & 17.634 .676 & 100,00 & \\
\hline
\end{tabular}

Fonte: MTE/RAIS (1997).

Tabela 14 - Distribuição dos trabalhadores em atividade em 31 de dezembro de 1997 de acordo com faixa de remuneração em dezembro de 1997 e o tamanho do estabelecimento

\begin{tabular}{|c|c|c|c|c|c|c|c|c|}
\hline \multirow[b]{2}{*}{$\begin{array}{c}\text { Faixa de } \\
\text { remuneração }\end{array}$} & \multicolumn{8}{|c|}{ Número de empregados e percentuais acumulados } \\
\hline & $\begin{array}{c}\text { De } \\
1 \text { a } 99\end{array}$ & $\begin{array}{l}\text { Percen- } \\
\text { tual } \\
\text { acumu- } \\
\text { lado }\end{array}$ & $\begin{array}{c}\text { De } \\
100 \\
a \\
499\end{array}$ & $\begin{array}{l}\text { Percen- } \\
\text { tual } \\
\text { acumu- } \\
\text { lado }\end{array}$ & $\begin{array}{c}\text { De } \\
500 \\
\text { a } \\
999\end{array}$ & $\begin{array}{l}\text { Percen- } \\
\text { tual } \\
\text { acumu- } \\
\text { lado }\end{array}$ & $\begin{array}{c}1.000 \\
\text { ou mais }\end{array}$ & $\begin{array}{l}\text { Percen- } \\
\text { tual } \\
\text { acumu- } \\
\text { lado }\end{array}$ \\
\hline Até 0,50 & 27.395 & 0,27 & 10.539 & 0,25 & 3.944 & 0,27 & 6.590 & 0,30 \\
\hline 0,51 a 1,00 & 561.269 & 5,88 & 73.071 & 2,01 & 24.909 & 2,00 & 40.488 & 2,17 \\
\hline 1,01 a 1,50 & 1.298 .408 & 18,86 & 238.091 & 7,74 & 74.036 & 7,15 & 129.514 & 8,16 \\
\hline 1,51 a 2,00 & 1.480 .108 & 33,65 & 361.574 & 16,44 & 101.968 & 14,23 & 145.204 & 14,87 \\
\hline 2,01 a 3,00 & 2.548 .381 & 59,12 & 804.622 & 35,81 & 230.187 & 30,22 & 260.369 & 26,90 \\
\hline 3,01 a 4,00 & 1.313 .402 & 72,25 & 625.038 & 50,85 & 211.524 & 44,92 & 229.242 & 37,49 \\
\hline 4,01 a 5,00 & 743.014 & 79,67 & 433.563 & 61,28 & 159.817 & 56,02 & 180.253 & 45,81 \\
\hline 5,01 a 7,00 & 739.798 & 87,06 & 524.151 & 73,89 & 198.909 & 69,84 & 275.247 & 58,53 \\
\hline 7,01 a 10,00 & 523.603 & 92,30 & 396.626 & 83,44 & 151.151 & 80,34 & 257.646 & 70,43 \\
\hline 10,01 a 15,00 & 351.554 & 95,81 & 297.160 & 90,59 & 116.813 & 88,45 & 231.248 & 81,12 \\
\hline 15,01 a 20,00 & 158.843 & 97,40 & 141.125 & 93,99 & 57.391 & 92,44 & 129.034 & 87,08 \\
\hline Mais de 20,0 & 260.325 & 100,00 & 249.863 & 100,00 & 108.856 & 100,00 & 279.671 & 100,00 \\
\hline Total & 10.006 .100 & & 4.155 .423 & & 1.439 .505 & & 2.164 .506 & \\
\hline
\end{tabular}

Obs.: Exclui indivíduos empregados nos setores de extração mineral, agropecuária e administração pública.

Fonte: MTE/RAIS (1997). 
formal da economia, que representa o universo atual da previdência privada fechada. ${ }^{6}$ Em 1997, havia aproximadamente 2,5 milhões de pessoas empregadas no setor formal (excluindo agropecuária, extração mineral, administração pública e ignorados) com rendimentos superiores a dez salários mínimos (Tabela 14). Trata-se, aí, de um grupo que teria necessidade de um plano privado de aposentadoria e que poderia ser coberto pelos tipos de planos atualmente existentes. O problema é que quase $30 \%$ desse contingente está empregado em estabelecimentos com menos de 100 funcionários, o que significa uma baixa probabilidade de acesso a um plano privado patrocinado pelo empregador.

A esse primeiro grupo-alvo, podem-se acrescentar os cerca de 1,49 milhão de indivíduos empregados em estabelecimentos com 1.000 ou mais funcionários e com rendimentos inferiores a dez salários mínimos. Se aplicássemos uma taxa de cobertura semelhante à dos Estados Unidos (70\%) para esse tipo de estabelecimento, ter-se-ia um universo de 1,04 milhão de indivíduos. Um sistema bem desenhado e com os incentivos apropriados poderia, pois, ter abarcado entre 3,5 a 4 milhões de indivíduos empregados no setor formal no ano de $1997 .^{7}$ Isso representa mais do dobro do contigente efetivamente coberto (participantes ativos) naquele ano (Tabela 16). Uma avaliação mais generosa poderia simplesmente aplicar aos dados brasileiros às taxas de cobertura en- contradas nos EUA de acordo com o tamanho do estabelecimento (Tabela 15). Nesse caso, o número potencial de indivíduos cobertos subiria para 7,3 milhões. Obviamente, esse exercício tem pouca validade devido às diferenças nos padrões de remuneração, emprego e faturamento entre as empresas dos dois países, mas, na melhor das hipóteses, pode ser encarado como um teto da previdência fechada nos seus moldes atuais.

QUANDO SE OBSERVA O NÚMERO DE INDIVÍDUOS EFETIVAMENTE COBERTOS PELA PREVIDÊNCIA PRIVADA FECHADA, FICA CLARO QUE HÁ UM SIGNIFICATIVO ESPAÇO DE CRESCIMENTO. MAIS

$$
\begin{gathered}
\text { AINDA, NOTA-SE QUE, NOS } \\
\text { ÚLTIMOS ANOS, O CRESCIMENTO } \\
\text { DO SETOR TEM SIDO PÍFIO. }
\end{gathered}
$$

Um modelo de previdência privada que permitisse a criação de planos fechados por organizações não patrocinadoras (órgãos de classe, sindicatos) poderia ainda estender a cobertura da previdência privada fechada aos cerca de 2,5 milhões de indivíduos ocupados por conta própria e empregadores (Tabela 3) com rendimentos superiores a dez salários mínimos em 1997.

Tabela 15 - Cobertura potencial aplicando-se as taxas dos EUA por tamanho de estabelecimento

\begin{tabular}{|l|c|c|c|}
\hline \multicolumn{1}{|c|}{$\begin{array}{c}\text { Tamanho do } \\
\text { estabelecimento }\end{array}$} & $\begin{array}{c}\text { No de indivíduos } \\
\text { empregados }\end{array}$ & $\begin{array}{c}\text { Taxa de cobertura } \\
\text { nos EUA }\end{array}$ & $\begin{array}{c}\text { No de indivíduos } \\
\text { potencialmente cobertos }\end{array}$ \\
\hline De 1 a 4 & 1.866 .691 & 0,12 & 224.003 \\
\hline De 5 a 9 & 1.712 .534 & 0,12 & 205.504 \\
\hline De 10 a 19 & 1.902 .191 & 0,24 & 456.526 \\
\hline De 20 a 49 & 2.473 .849 & 0,305 & 754.524 \\
\hline De 50 a 99 & 1.827 .592 & 0,457 & 835.210 \\
\hline De 100 a 249 & 2.356 .870 & 0,545 & 1.284 .494 \\
\hline De 250 a 499 & 1.714 .615 & 0,634 & 1.087 .066 \\
\hline De 500 a 999 & 1.444 .275 & 0,613 & 885.341 \\
\hline 1.000 ou mais & 2.203 .229 & 0,715 & 1.575 .309 \\
\hline Total & 17.501 .846 & & 7.307 .976 \\
\hline
\end{tabular}

Obs.: Estão excluídos os indivíduos empregados nos setores de agropecuária, extração mineral, administração pública e ignorados.

Fonte: MTE/RAIS (1997). 
Quando se observa o número de indivíduos efetivamente cobertos pela previdência privada fechada, fica claro que há um significativo espaço de crescimento. Mais ainda, nota-se que, nos últimos anos, o crescimento do setor tem sido pífio. $\mathrm{Na}$ verdade, o número de participantes ativos em julho de 1999 era inferior ao verificado em dezembro de 1995. O

O ESFORÇO EDUCACIONAL DEVE SER COMPLEMENTADO PELO DESENHO DE PLANOS MAIS FLEXÍVEIS E DE BAIXO CUSTO, AFINADOS COM AS CARACTERÍSTICAS ATUAIS DO MERCADO DE TRABALHO.

número total de participantes (ativos e assistidos) também decai de dezembro de 1997 para julho de 1999. A questão que se coloca, portanto, é como redesenhar o sistema de previdência privada fechada de modo a deter o processo de encolhimento e colocá-lo numa nova trajetória de expansão.

Os esforços deveriam ser concentrados em três frentes:

a) Um esforço educativo para ampliar o grau de adesão dos empregados nas empresas que oferecem planos de previdência privada e para estimular as empresas com características semelhantes às das atuais patrocinadoras (número de empregados, setor de atividade econômica e faturamento) a oferecer esse tipo de benefício.

b) Alterações no desenho dos planos atuais (regulação e incentivos) para expandir sua penetração em pequenas e médias empresas.

c) Mudanças na legislação de modo a permitir a criação de planos fechados de previdência pri- vada por entidades de classe e órgãos profissionais, atendidas certas condições relativas às características dessas entidades, à sua fiscalização e à profissionalização do processo de gestão de ativos. ${ }^{8}$ Essa medida tem o potencial de atingir o contingente da PEA ocupado por conta própria ou os empregadores com rendimentos mensais superiores a dez salários mínimos. A medida facilitará, ainda, o ingresso no sistema de previdência fechado dos empregados com rendimentos superiores a dez salários mínimos das empresas que não oferecem planos de previdência. $\mathrm{O}$ uso de laços de afinidade, por meio de sindicatos e associações profissionais, facilitará enormemente a criação de planos de previdência privada, à medida que reduzirá os custos associados à divulgação e distribuição dos planos. Os dados da PNAD de 1997 mostram que o número de pessoas sindicalizadas com rendimentos mensais superiores a dez salários mínimos era de 1.652.698. O Reino Unido divulgou, em 1999, um projeto que prevê a criação de planos privados de previdência, passíveis de serem organizados nesses moldes (Rabelo, 1999).

No que tange à legislação, há um outro aspecto que contribui para o baixo crescimento do sistema fechado de previdência privada nos últimos anos: a tributação. Desde 1983, os fundos de pensão estão em litígio judicial com a Secretaria da Receita Federal em função da intenção da Receita de tributar os ativos dos fundos durante o período de acumulação. Uma vez que o tratamento fiscal diferenciado constitui o principal incentivo para o ingresso na previdência privada (Rabelo, 1997), é muito provável que potenciais patrocinadoras estejam esperando a resolução dessa questão para

Tabela 16 - População abrangida pela previdência complementar fechada

\begin{tabular}{|l|c|c|c|}
\hline & Ativos & Assistidos & Total \\
\hline 1995 & 1.826 .231 & 346.214 & 2.172 .445 \\
\hline 1996 & 1.795 .780 & 383.922 & 2.179 .702 \\
\hline 1997 & 1.788 .051 & 426.307 & 2.214 .358 \\
\hline 1998 & 1.650 .552 & 460.475 & 2.111 .027 \\
\hline Julho de 1999 & 1.723 .013 & 489.965 & 2.212 .978 \\
\hline
\end{tabular}

Fonte: Secretaria de Previdência Complementar (1999). 
decidir se criam ou não um plano. Caso prevaleça a posição da Receita Federal, é duvidoso que a previdência privada fechada consiga prosperar no país.

\section{CONCLUSÃO}

A expansão da previdência privada fechada no Brasil encontra duas fortes restrições estruturais: a desigualdade na distribuição da renda (pequeno universo de pessoas com rendimentos mensais superiores a dez salários mínimos) e a concentração do emprego em pequenas empresas. Nos últimos quatro anos, o crescimento da previdência complementar foi insignificante; de fato, houve uma queda no número de par- ticipantes ativos entre dezembro de 1996 e dezembro de 1998.

Para lidar com tais restrições, faz-se necessário um esforço educacional para divulgar a previdência privada entre empregados e empregadores. Esse esforço deve ser complementado pelo desenho de planos mais flexíveis e de baixo custo, afinados com as características atuais do mercado de trabalho. Além disso, a criação da figura do instituidor poderá levar algumas das vantagens da previdência privada fechada para os trabalhadores autônomos, contribuindo com o esforço de ampliação da cobertura previdenciária no país e com a geração de poupança de longo prazo. A resolução da pendência tributária que envolve a previdência privada fechada é outra medida que facilitará a expansão do sistema complementar privado.

REFERÊNCIAS BIBLIOGRÁFICAS

BANCO MUNDIAL. Averting the old-age crisis: policies to protect the old and promote growth. New York : Oxford University Press, 1994.

EMPLOYEE BENEFIT RESEARCH INSTITUTE (EBRI). Small Employer Retirement Survey (SERS). Washington, 1999.

EVEN, W. E., McPHERSON, D. A. Employer size and labor turnover: the role of pensions. Industrial \& Labor Relations Review, v. 49, n. 4, p. 707-728, 1996.

HINZ, R., TURNER, J. A. Pension coverage initiatives: why don't workers participate? In: MITCHELL, 0., SCHIBER, S. (Eds.). Living with defined contribution pensions: remaking responsibility for retirement. Philadelphia PRC/University of Pennsylvania Press, 1998.
INSTITUTO BRASILEIRO DE GEOGRAFIA E ESTATÍSTICA. Pesquisa Nacional por Amostra de Domicílio - PNAD. Rio de Janeiro : IBGE, 1997.

MINISTÉRIO DO TRABALHO E EMPREGO. Relação Anual de Informação Social - RAIS. Rio de Janeiro : Datamec, 1997.

NAJBERG, S., OLIVEIRA, P. A. A dinâmica recente do emprego formal no Brasil. Rio de Janeiro : BNDES, 1999. Mimeo.

ORSZAG, P. How the "cross tresting" pension loophole harms low-and-moderate-income workers. London : Center on Budget and Policy Research, Mar. 2, 2000.
RABELO, F. M. A tributação dos fundos de pensão In: CONGRESSO NACIONAL DOS FUNDOS DE PENSÃO, 18., 1997, São Paulo. São Paulo : Associação Brasileira das Entidades Fechadas de Previdência Privada, 1997.

RABELO, F. M. Relatório 1 do Projeto "Estudo técnico sobre o potencial de crescimento da previdência complementar no Brasil". Convênio de Cooperação Técnica BID/MPAS/SPC ATN/MT 5949-BR. Brasília, 1999.

SECRETARIA DE PREVIDÊNCIA COMPLEMENTAR. Informações básicas: previdência complementa fechada. Brasília,1999.
Este artigo foi elaborado a partir do Relatório 1 do "Estudo técnico sobre o potencial de crescimento da previdência complementar no Brasil" realizado para a Secretaria de Previdência Complementar do Ministério da Previdência e Assistência Social. Agradeço os comentários de Carlos Eduardo Esteves Lima, Secretário Adjunto de Previdência Complementar. Sheila Najberg fez sugestões valiosas em relação ao uso dos dados da RAIS.

1. Previdência privada fechada refere-se a fundos de pensão patrocinados por empresas e algumas outras organizacõos para os seus funcionários. 0 acesso a esses planos, portanto, é restrito a indivíduos empregados em empresas que oferecem tal benefício. A previdência privada aberta compreende planos individuais ou coletivos negociados por bancos e seguradoras. No Brasil, a previdência privada fechada é bem mais representativa do que a aberta, tanto em termos de participantes quanto em ativos administrados.
2. Os dados têm um problema: não está claro se 0 que está sendo considerado é o tamanho da empresa ou o tamanho do estabelecimento (uma empresa pode ter vários estabelecimentos)

3. Atualmente, planos fechados exigem a figura de um patrocinador, uma organização que verta contribuicões em favor dos participantes do plano. Em 1999, a Secretaria de Previdência Complementar apresentou um Projeto de Lei que permite a criação de um plano fechado por organizações que não estariam obrigadas a fazer contribuições em favor dos participantes; atuariam simplesmente como instituidoras do plano, cuidando da sua distribuição e administração. Isso abriria espaço para que associacões profissionais e sindicatos instituíssem planos fechados para os seus membros.

4. Najberg e Oliveira (1999) usaram o número de trabalhadores em atividade em 31 de dezembro de 1997 como indicador da dimensão do mercado de trabalho formal no Brasil seguindo sugestão de técnicos do Ministério do Trabalho e Emprego.
5. Não é possível analisar a distribuição do emprego formal de acordo com a faixa de rendimentos e 0 tamanho da empresa. A análise segundo o tamanho do estabelecimento tende a superestimar o número de indivíduos empregados em unidades menores, mas essas distorções não comprometem os resultados da análise.

6. Como esses planos só podem ser criados por entidades patrocinadoras, eles atualmente só abarcam indivíduos empregados no setor formal da economia.

7. Nesse cálculo não estão incluídos os indivíduos com rendimentos inferiores a dez salários mínimos empregados em estabelecimentos com menos de 1.000 funcionários. A estimativa feita, portanto, pode ser considerada razoavelmente conservadora.

8. Como já foi dito, tramita no Congresso Naciona desde 1999 um Projeto de Lei (PL 10/99) que, entre outras coisas, cria a figura do instituidor. 